\title{
The Structural, Impedance and Dielectric A Ferrite Core of Iron Manganite and Its Composite
}

\author{
Y. E. Gunanto ${ }^{1}{ }^{*}$, H. Sitompul ${ }^{1}$, M. P. Izaak ${ }^{1}$ and W. A. Adi ${ }^{2}$ \\ 1 Dept. of Physics of Edu., Faculty of Education, Universitas Pelita Harapan, Karawaci, Tangerang 15811, Indonesia \\ ${ }^{2}$ Research and Technology Center for Nuclear Advanced Materials, National Research and Innovation Agency, Indonesia
}

\begin{abstract}
Samples with single-phase $\mathrm{MnFeO}_{3}$ and multiphase $\mathrm{MnFeO}_{3} / \mathrm{ZnFe}_{2} \mathrm{O}_{4}$ (30/70), and $\mathrm{MnFeO}_{3} / \mathrm{ZnFe}_{2} \mathrm{O}_{4} / \mathrm{LaMnO}_{3}(30 / 40 / 30)$ have been successfully prepared as ferrite cores by the solidstate reaction method using high energy milling. Crystal structure, surface morphology, impedance, AC-conductivity and dielectric quantities, such as dielectric constant and dielectric loss have been studied. The crystalline structures for $\mathrm{MnFeO}_{3}, \mathrm{ZnFe}_{2} \mathrm{O}_{4}$, and $\mathrm{LaMnO}_{3}$ are hexagonal, cubic and monoclinic, The Rietveld program used for $\mathrm{XRD}$ analysis resulted in the composition fractions of single phase $\mathrm{MnFeO}_{3}$, multiphase $\mathrm{MnFeO}_{3} / \mathrm{ZnFe}_{2} \mathrm{O}_{4}(31 / 69)$, and $\mathrm{MnFeO}_{3} / \mathrm{ZnFe}_{2} \mathrm{O}_{4} / \mathrm{LaMnO}_{3}(31 / 40 / 29)$. The morphology of all samples has a heterogeneous shape and size with low porosity. The single-phase impedance of $\mathrm{MnFeO}_{3}$ is higher than the multiphase sample. The conductivity of the three samples has the same pattern, which is relatively constant at low frequencies and begins to increase at frequencies above $10 \mathrm{kHz}$. The dielectric constant and dielectric loss $(\tan \partial)$ have high values at low frequencies, decrease exponentially with increasing frequency and are relatively fixed at high frequencies.
\end{abstract}

ARTICLE HISTORY

Received: 12 May 2021

Revised: 6 October 2021

Accepted: 13 October 2021

KEYWORDS

Ferrite core,

Milling,

Single-multiphase,

Dielectric constant,

Loss tangent

\section{INTRODUCTION}

Ferrite is a ceramic compound of transition metals with oxygen, which is ferrimagnetic but not conductive. The ferrite used in transformer or electromagnetic cores contains iron oxide combined with manganese [1-4], zinc, and / or nickel compounds [5-8]. These materials have high resistivity or low electrical conductivity which prevents eddy currents in the core from causing energy loss.

Iron manganite $\left(\mathrm{MnFeO}_{3}\right)$ has its impedance and dielectric constant which decreases with increasing frequency [1, 4]. The electrical resistivity of nickel zinc nano ferrites is highly dependent on the size of the crystallinity and with increasing frequency, the dielectric constant decreases [5,6], and the value of $\tan \partial$ also decreases [7, 8]. The perovskite $\mathrm{LaMnO}_{3}$ compound, with increasing frequency will also experience a decrease in impedance, dielectric and $\tan \partial$ constants [9], and also their electrical conductivity [10].

Several methods have been used for the sample preparation process, for example solid reaction [1, 10], sono-chemical [2], sol-gel auto-combustion [4, 6], coprecipitation [5], the polymerizable complex [9]. Of the several methods, the solid reaction is the easiest and cheapest method.

This paper will discuss the structure, surface morphology, impedance, dielectric constant and loss tangent (tan) of single phase $\mathrm{MnFeO}_{3}$, two phases $\mathrm{MnFeO}_{3} / \mathrm{ZnFe}_{2} \mathrm{O}_{4}(30 / 70)$, and three phases $\mathrm{MnFeO}_{3} / \mathrm{ZnFe}_{2} \mathrm{O}_{4} / \mathrm{LaMnO}_{3}(30 / 40 / 30)$. All samples were processed using the solid reaction method by milling in a wet state for 10 hours.

\section{EXPERIMENTAL METHOD}

\section{Materials and Instruments}

Each sample is made with the following reaction in Equation 1 to 3.

$$
\begin{aligned}
\mathrm{Mn}_{2} \mathrm{O}_{3}+\mathrm{Fe}_{2} \mathrm{O}_{3} & \rightarrow 2 \mathrm{MnFeO}_{3} \\
\mathrm{ZnO}+\mathrm{Fe}_{2} \mathrm{O}_{3} & \rightarrow \mathrm{ZnFe}_{2} \mathrm{O}_{3} \\
\mathrm{La}_{2} \mathrm{O}_{3}+2 \mathrm{MnO}_{2} & \rightarrow 2 \mathrm{LaMnO}_{3}
\end{aligned}
$$

To identify the phases formed, the composition, crystal structure and lattice parameters used a Philips PW1710 X-ray diffractometer (XRD), $C u-K \alpha$ radiation $(\lambda=1.5406 \AA$ ). Surface morphology was characterized using the scanning electron microscopy (SEM) type JEOL (JED-2300). While the LCR meter, type HIOKI-5020 is used for measuring impedance, electrical conductivity, dielectric constant and loss tangent $(\tan \partial)$ in a frequency of $1-10^{5} \mathrm{~Hz}$. 


\section{Method and Procedure}

Each raw material has a purity of not less than $99 \%$. Each mixture was put into a stainless-steel vial filled with ethanol up to two-thirds and given stainless steel balls. The sample weight ratio: iron balls is 1:10. Each mixture was then milled for 5 hours, then sintered in air at $1000^{\circ} \mathrm{C}$ for 5 hours.

With a ratio of $30 / 70$ a composite $\mathrm{MnFeO}_{3} / \mathrm{ZnFe}_{2} \mathrm{O}_{4}$ was made. To ensure a homogeneous mixture, these composites were milled for one hour. The same was done for the $\mathrm{MnFeO}_{3} / \mathrm{ZnFe}_{2} \mathrm{O}_{4} / \mathrm{LaMnO}_{3}$.

\section{RESULT AND DISCUSSION}

The diffraction patterns resulting from characterization using XRD can be seen in Figure 1 (a). The diffraction peaks of each sample are shown, especially for the composite samples $\mathrm{MnFeO}_{3} / \mathrm{ZnFe}_{2} \mathrm{O}_{4}$ and $\mathrm{MnFeO}_{3} / \mathrm{ZnFe}_{2} \mathrm{O}_{4} / \mathrm{LaMnO}_{3}$. From the three diffraction patterns, $\mathrm{MnFeO}_{3}, \mathrm{MnFeO}_{3} / \mathrm{ZnFe}_{2} \mathrm{O}_{4}$, and $\mathrm{MnFeO}_{3} / \mathrm{ZnFe}_{2} \mathrm{O}_{4} / \mathrm{LaMnO}_{3}$ there was no shift in the diffraction peaks.
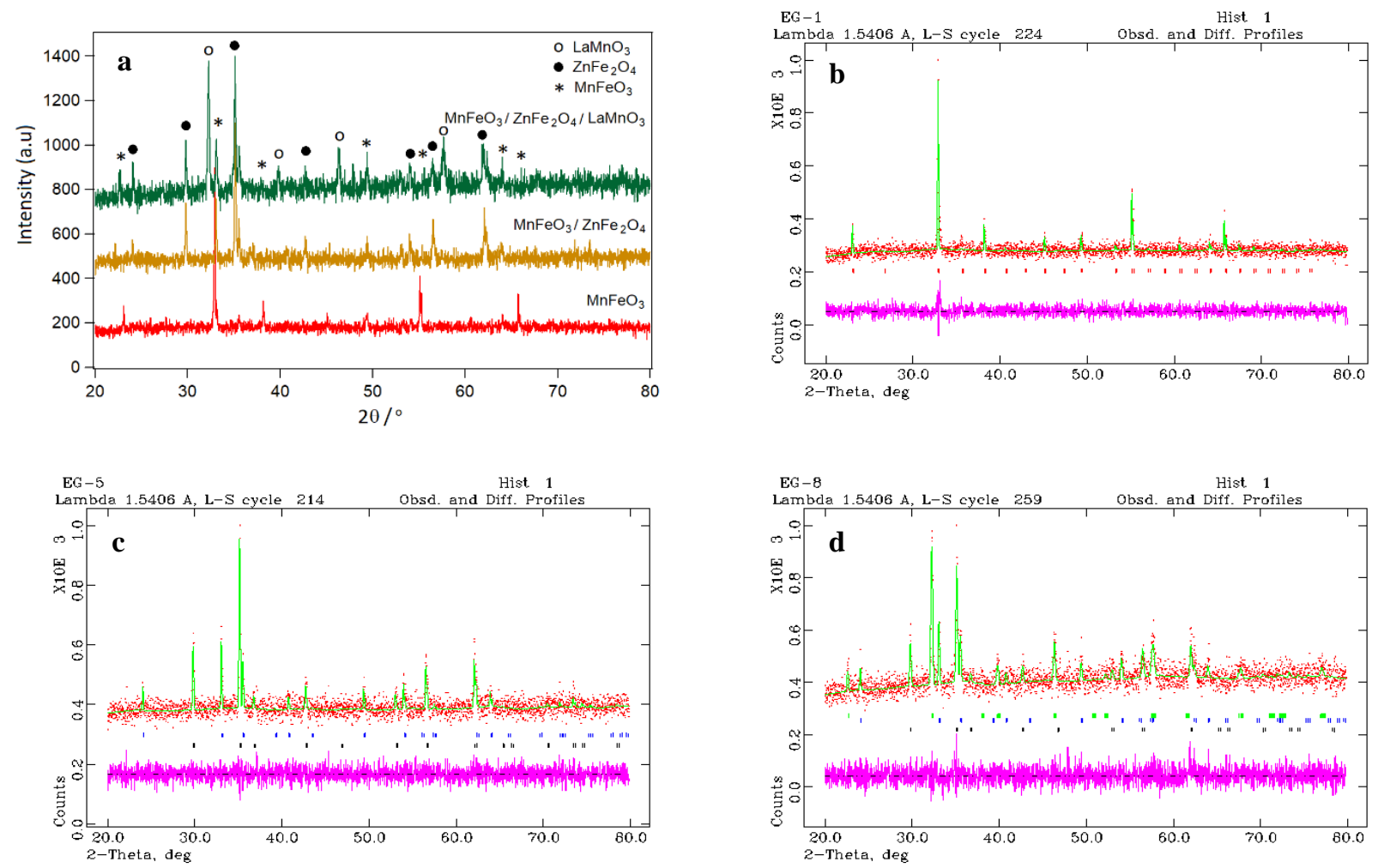

Figure 1. Diffraction patterns (a) Refined results with the GSAS program, (b) sample EG-1, (c) sample EG-5, and (d) sample EG-8.

The results of refining using the GSAS program for each sample can be seen in Figures 1 (b), (c), and (d) for samples of $\mathrm{MnFeO}_{3}$ (here in after referred to as EG-1), $\mathrm{MnFeO}_{3} / \mathrm{ZnFe}_{2} \mathrm{O}_{4} 30 / 70$ (EG-5), and $\mathrm{MnFeO}_{3} / \mathrm{ZnFe}_{2} \mathrm{O}_{4} / \mathrm{LaMnO}_{3} 30 / 40 / 30$ (EG-8), respectively. The results of the analysis of XRD diffraction patterns using the GSAS program, the fractions formed were single-phase for $\mathrm{MnFeO}_{3}, \mathrm{MnFeO}_{3} / \mathrm{ZnFe}_{2} \mathrm{O}_{4}$ (31/69), and $\mathrm{MnFeO}_{3} / \mathrm{ZnFe}_{2} \mathrm{O}_{4} / \mathrm{LaMnO}_{3}$ (31/40/29). The complete results can be seen in Table 1. The results of the obtained fractions are not much different from the planned fractions. The crystal structure of each sample is $\mathrm{MnFeO}_{3}$ (hexagonal, space group $\mathrm{R}-3 \mathrm{c}$ ), $\mathrm{ZnFe}_{2} \mathrm{O}_{4}$ (cubic, space group F m -3 m), and $\mathrm{LaMnO}_{3}$ (monoclinic, space group I 12 / a 1). The same results were obtained by other researchers, namely $\mathrm{MnFeO}_{3}$ with a hexagonal structure [11], $\mathrm{ZnFe}_{2} \mathrm{O}_{4}$ with a cubic crystal structure [5], and $\mathrm{LaMnO}_{3}$ being monoclinic [12]. The complete results of XRD characterization can be seen in Table 1.

Table 1. XRD characterization results: structure, space group, lattice parameters using the GSAS program

\begin{tabular}{llrrrrrrr}
\hline Sample & System/SG & $A(\AA)$ & $B(\AA)$ & $c(\AA)$ & $V(\AA)^{3}$ & $\rho\left(\mathrm{g} / \mathrm{cm}^{3}\right)$ & $\chi^{2}$ & Fraction $(\%)$ \\
\hline EG-1 & Hexagonal/R-3c & $5.0364(6)$ & $5.0364(6)$ & $13.7436(6)$ & $302.5(1)$ & 5.280 & 1.082 & 100 \\
EG-5 & Hexagonal/R-3c & $5.0354(9)$ & $5.0354(9)$ & $13.748(3)$ & $301.9(1)$ & 5.270 & 1.084 & 31 \\
& Cubic/F m -3 m & $8.440(1)$ & $8.440(1)$ & $8.440(1)$ & $601.2(2)$ & 5.326 & & 69
\end{tabular}




\begin{tabular}{lllllllll} 
EG-8 & Hexagonal/R-3c & $5.0354(1)$ & $5.0354(1)$ & $13.742(6)$ & $301.7(2)$ & 5.272 & 1.186 & 31 \\
& Cubic/F m -3 m & $8.459(2)$ & $8.459(2)$ & $8.459(2)$ & $605.4(4)$ & 5.289 & 40 \\
Monoclinic/I 1 2/a 1 & $7.829(4)$ & $5.531(3)$ & $5.521(4)$ & $239.1(2)$ & 6.375 & 29 \\
\hline
\end{tabular}

Figures 2 (a) - (c) obtained from SEM, show the surface morphology for samples EG-1, EG-5 and EG-8, respectively. From the three SEM images, it appears that the size and shape of the particles are heterogeneous. According to M. V. Nikolic et al., The different sizes and shapes are a typical result of the solid reaction synthesis [1]. The microstructure density is greatly influenced by the heating temperature [13]. The denser microstructure will have better electrical properties [6]. From Figures 2 (b) and (c) From Figures 2(b) and (c), it appears agglomeration occurs. Thus, it can be said that the composites of the constituent materials have been evenly mixed.
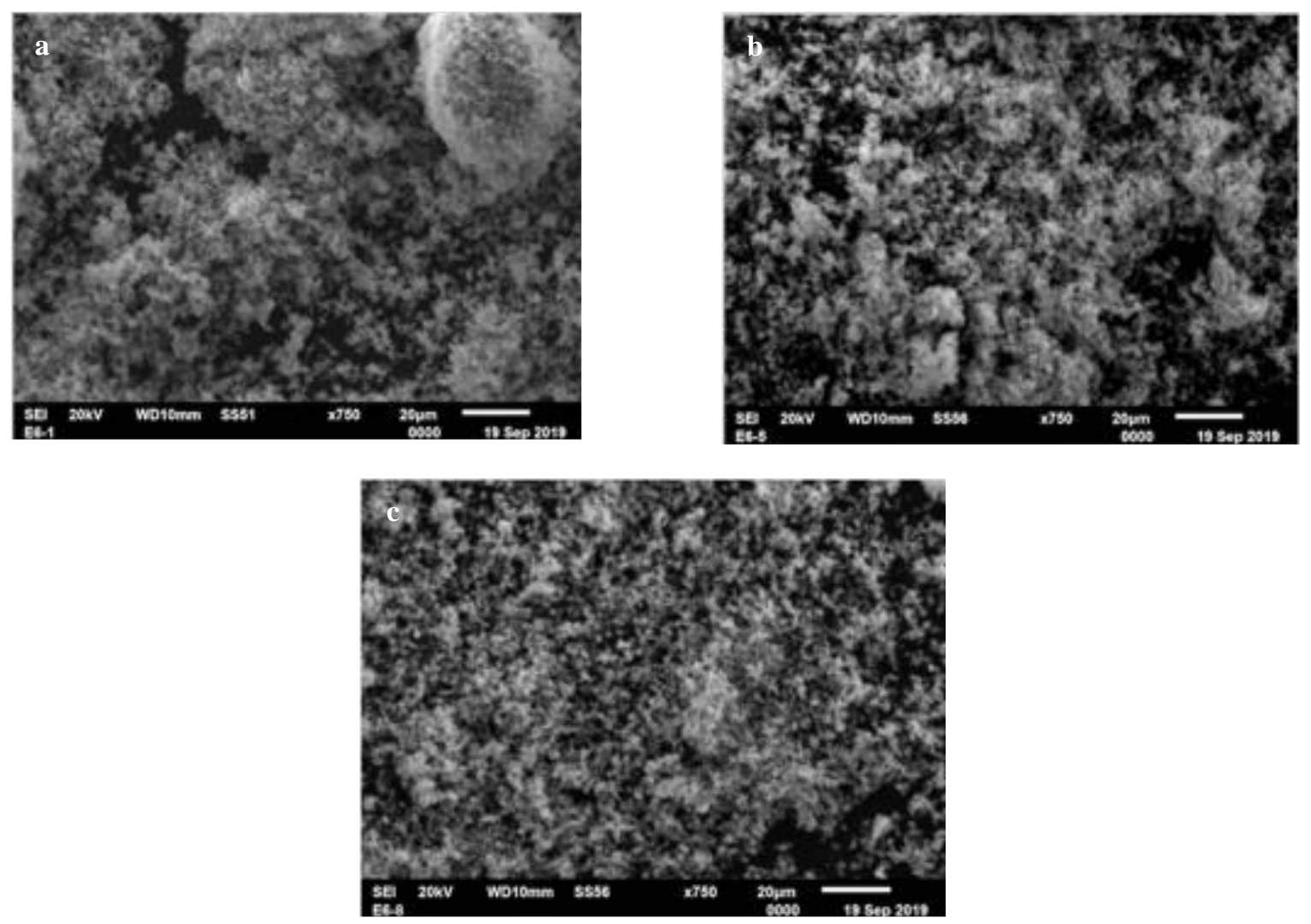

Figure 2. Surface morphology using SEM for samples (a) EG-1, (b) EG-5, and (c) EG-8

At room temperature, the LCR meter is used for measuring $\mathrm{Z}$ impedance, conductivity, dielectric, and loss factor in the frequency range $1-100 \mathrm{kHz}$.

Impedance $\mathrm{Z}$ is calculated using the Equation 4.

$$
Z=\left[R^{2}+\left(X_{L}-X_{C}\right)^{2}\right]^{1 / 2}
$$

where $\mathrm{R}=$ resistivity, $\mathrm{X}_{\mathrm{L}}=$ inductive reactance, and $\mathrm{X}_{\mathrm{C}}=$ capacitive reactance.

The plot of the frequency-dependent $\mathrm{Z}$ impedance curve at room temperature can be seen in Figure 3 . At the same frequency, the impedance of the EG-1 sample is greater than that of the EG-5 and EG- 8 samples. However, the impedance of each sample is relatively constant even though the frequency increases. Impedance is influenced by surface morphology. According to S. B. Khan et al., Impedance is related to the microstructure, such as the interface, grain, or grain boundaries of the polycrystalline sample [5]. Thus, the almost homogeneous surface morphology results in almost unchanged impedance values. However, the imaginary impedance value for the EG-1 sample is relatively constant, while for the EG-5 and EG-8 samples it decreases with increasing frequency. The frequency-independent value of $\mathrm{Z}$ can be explained due to the pure resistance of the grain. Meanwhile, the frequency dependent part is influenced by the resistance and capacitance of the grains simultaneously [9]. For the EG-5 and EG-8 samples, as the frequency increases, the imaginary impedance value decreases. The same thing was also obtained by S. G. Titova et al. [12]. 


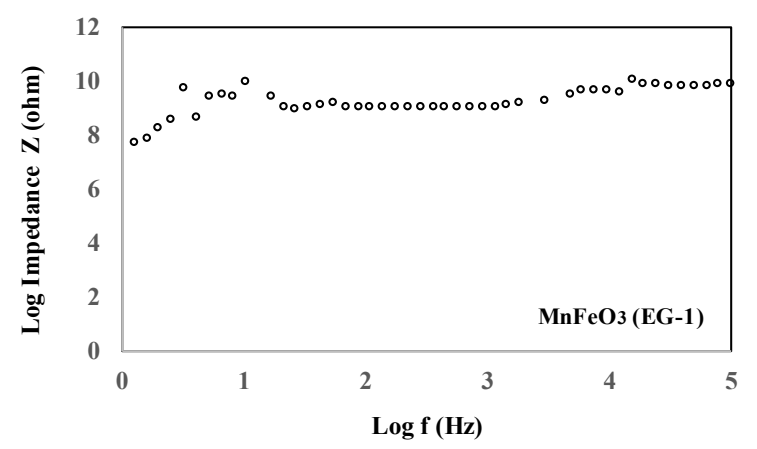

a
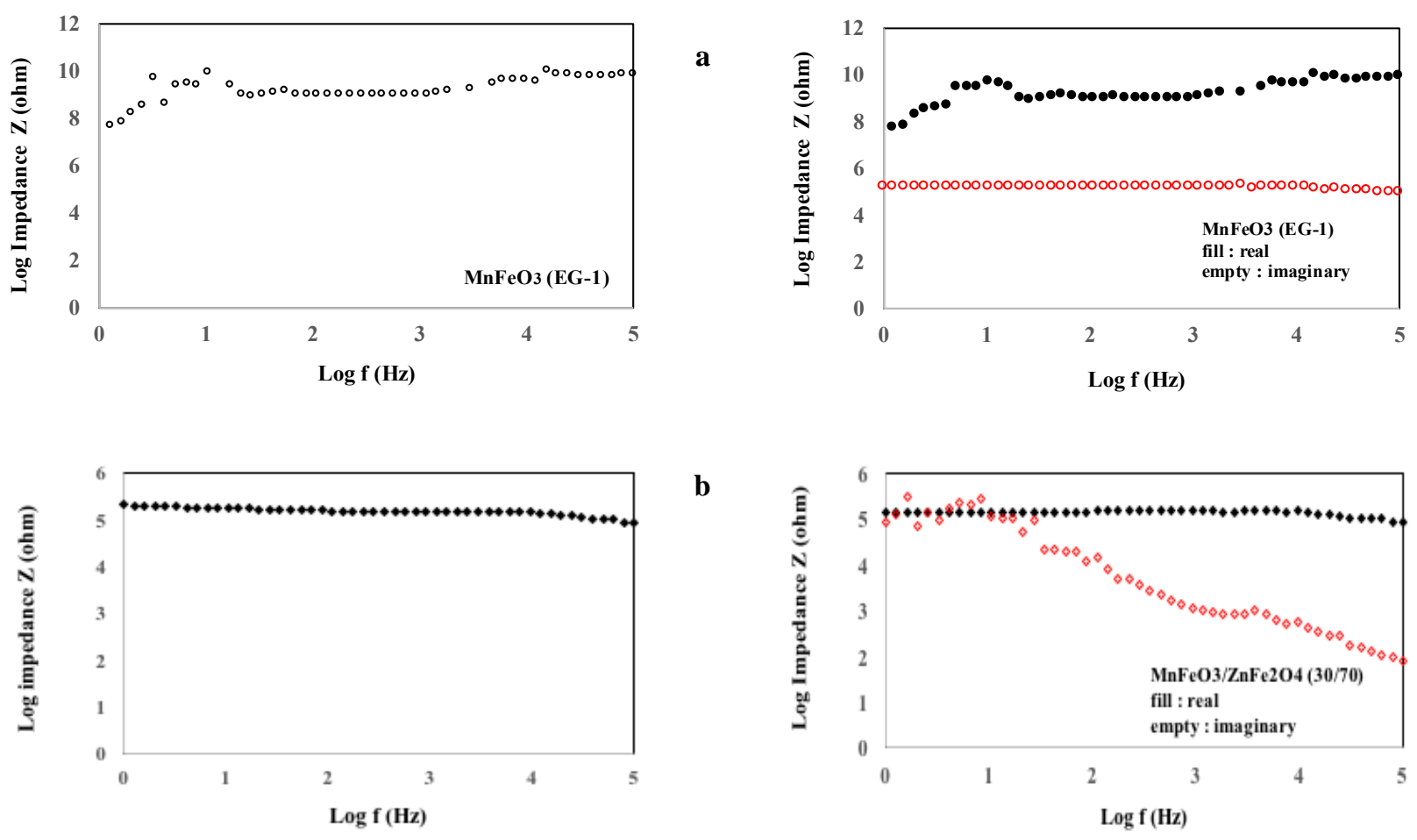

b
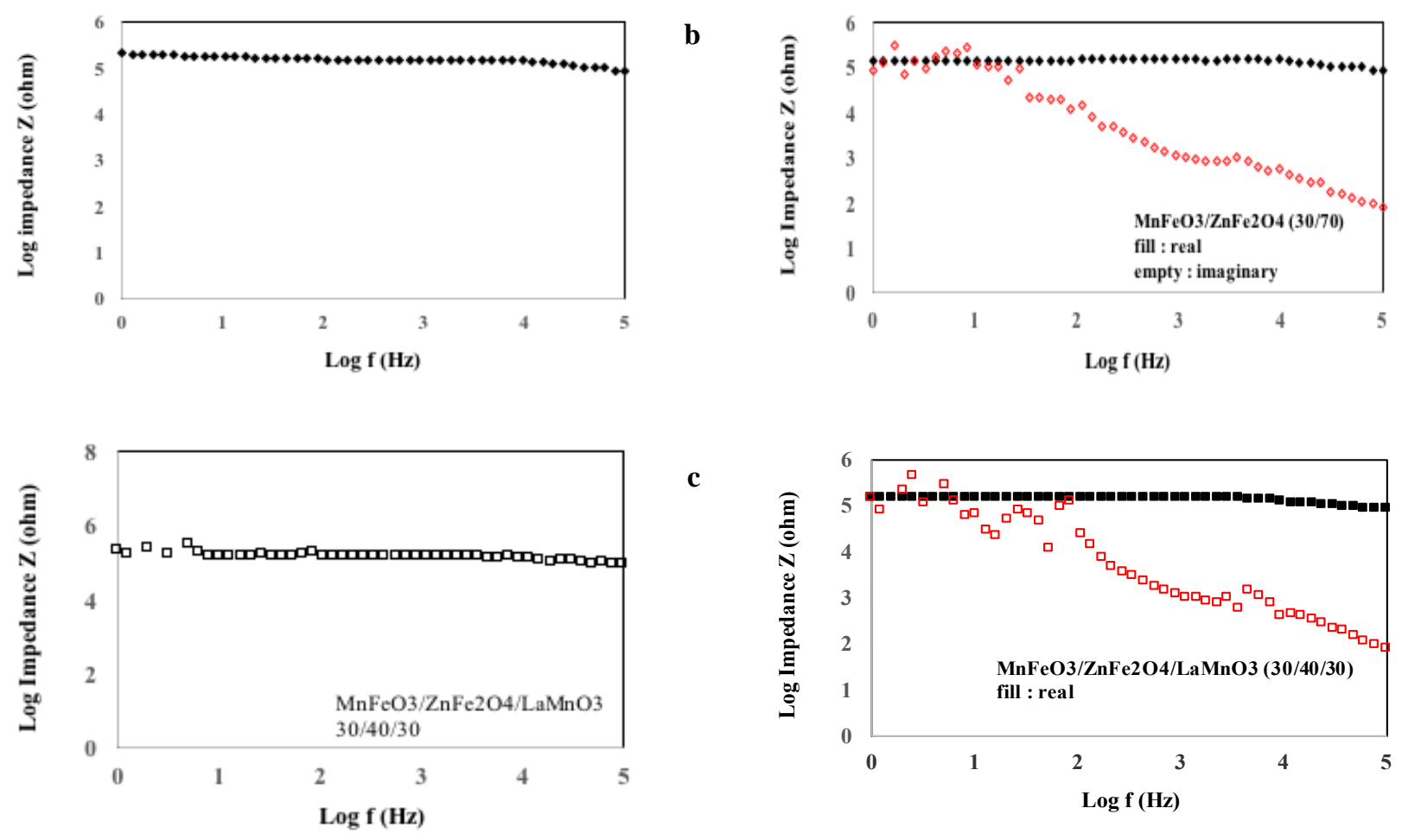

Figure 3. Plot of impedance as a function of frequency (total, real and imaginary impedance) on a log scale for samples (a) EG-1, (b) EG-5, and (c) EG-8

The plot of the conductivity dependence on frequency can be seen in Figure 4. The amount of conductivity is calculated by Equation 5 [14]:

$$
\sigma_{A C}^{\prime}=\frac{d}{r A}
$$

where $\sigma_{\mathrm{ac}}{ }^{\prime}$ is the AC-conductivity $(\mathrm{S} / \mathrm{cm}), d$ is the sample length $(\mathrm{cm}), r$ is the resistance (ohms), and $A$ is the crosssectional area of the sample $\left(\mathrm{cm}^{2}\right)$.

The conductivity is relatively constant up to $\log$ values $f$ to 4 (frequency $10 \mathrm{kHz}$ ) and begins to increase after $\log f=4$ (above $10 \mathrm{kHz}$ frequency). Increasing conductivity with increasing frequency can be explained because increasing frequency will increase the number of electron-jumps between $\mathrm{Fe}^{3+}$ and $\mathrm{Fe}^{2+}$ [4]. This is consistent with the Koops theory, where the conductor properties are due to grain, while grain boundaries are poorly conducting layers [15]. The real part of the dielectric constant $\left(\varepsilon^{\prime}\right)$ for all samples is calculated using Equation 6 [16]:

$$
\varepsilon^{\prime}=C d /\left(\varepsilon_{0} A\right)
$$

where $C$ is the capacitance (farad), $d$ is the thickness of the sample $(\mathrm{m}), \varepsilon_{0}$ is the permittivity of the vacuum $\left(8.86 \mathrm{x} 10^{-}\right.$ $\left.{ }^{12} \mathrm{~F} / \mathrm{m}\right)$, and $A$ is the cross-sectional area of the sample $\left(\mathrm{m}^{2}\right)$.

The frequency dependence of the dielectric constant (on a log scale) can be seen in Figure 5. As the frequency increases, all samples show a decrease in the dielectric constant. At high frequencies, the dielectric constant is relatively constant. Similar results were obtained by several other researchers [17-18]. 

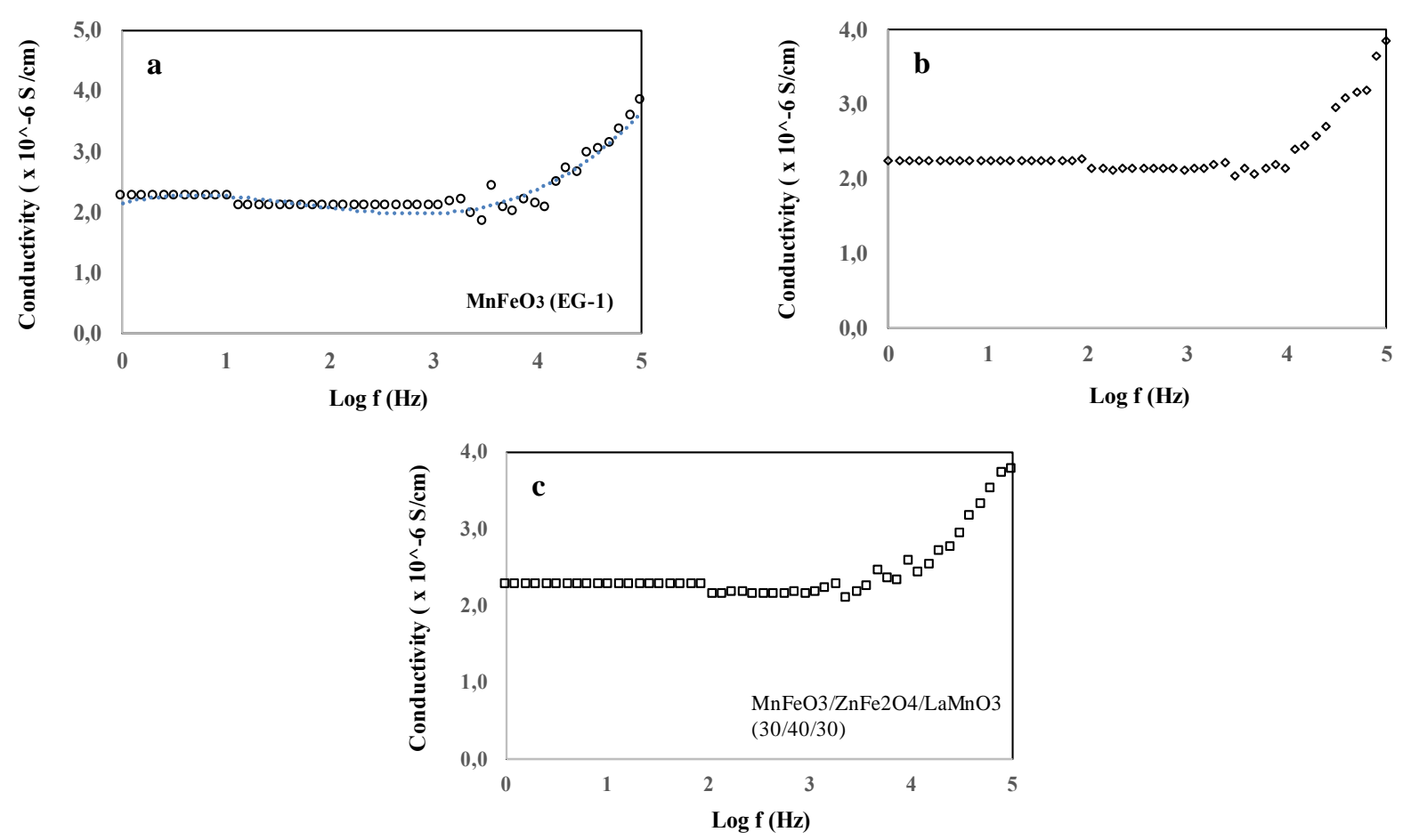

Figure 4. Frequency dependent conductivity for samples (a) EG-1, (b) EG-5, and (c) EG-8 at room temperature
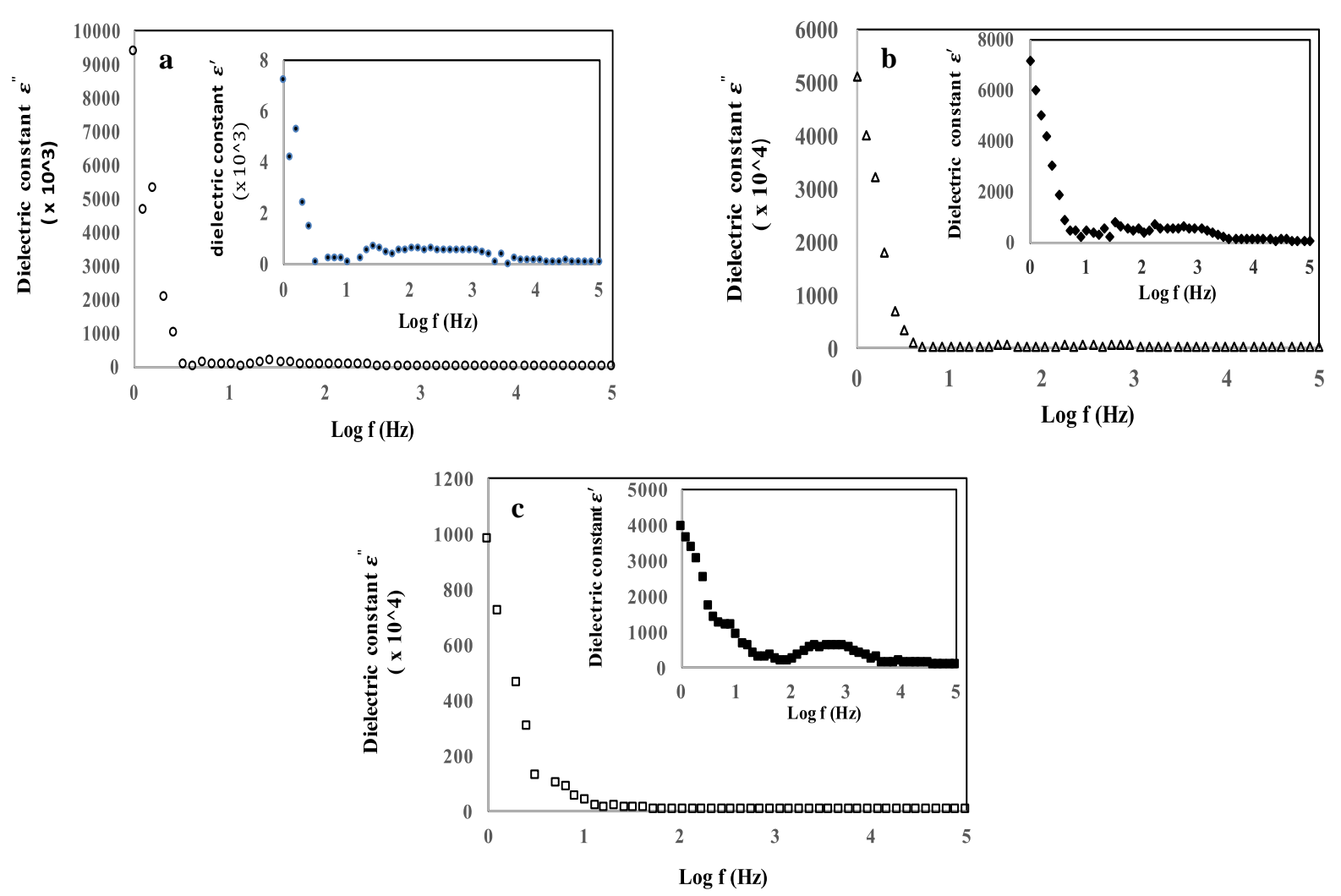

Figure 5. Frequency dependent dielectric constant for samples (a) EG-1, (b) EG-5, and (c) EG-8. Insert: real section

At the octahedral site, the frequency of the electron jumping between the $\mathrm{Fe}^{3+}$ ion and the $\mathrm{Fe}^{2+}$ ion when compared to the frequency of the applied AC field will be higher. This occurs in the low frequency area. Thus, the hopping electrons easily interact with the inversion of the applied electric field. This results in a high dielectric constant $\left(\varepsilon^{\prime}\right)$. Meanwhile, at high frequencies, an electron jump is required to move across the resistivity of the sample which results in disruption of the electron exchange between $\mathrm{Fe}^{3+}$ ions and $\mathrm{Fe}^{2+}$ ions. Thus, the dielectric constant value will be lower, according to the Koops model [16-17]. According to this model, ferrite consists of grain (good conductor) and grain boundaries (bad conductor). If the grain size decreases the number of grain boundaries will increase. This will have an impact on the 
dielectric constant of the sample, where the grains have a low dielectric constant. So that this sample is effective at high frequencies $[16,18]$.

Loss tangent $(\tan \partial)$, calculated by Equation 7.

$$
\tan \partial=\left(\sigma_{A C}^{\prime} A\right) /(\omega C d)
$$

where $\sigma_{A C}^{\prime}$ is the conductivity of the sample $(\mathrm{S} / \mathrm{m}), \mathrm{A}$ is the cross-sectional area of the sample $\left(\mathrm{m}^{2}\right), \omega=2 \pi f$ is the frequency (Hz), $C$ is the capacitance (Farad), and $d$ is the thickness of the sample (m).

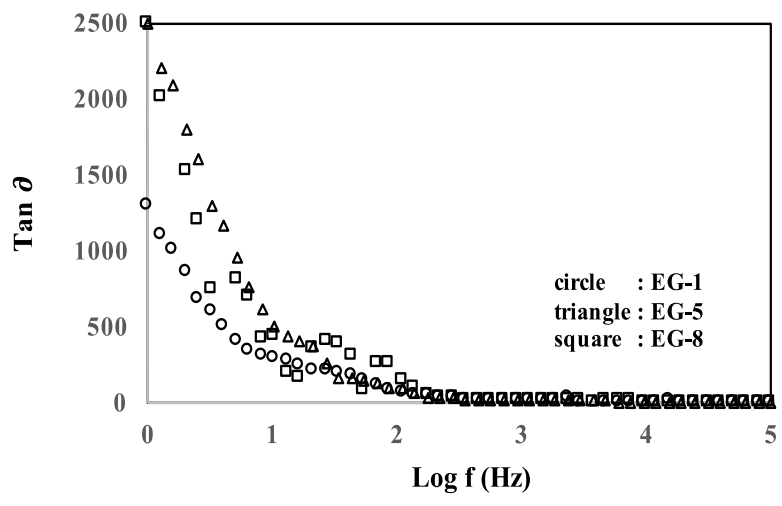

Figure 6. Loss tangent $(\tan \partial$ ) is frequency dependent for samples (a) EG-1, (b) EG-5, and (c) EG-8

The loss tangent (tan) to frequency (log scale) at room temperature shows the same dispersion as the dielectric constant, which decreases exponentially with increasing frequency, decreases rapidly at low frequencies then slows down at high frequencies. See Figure 6. The same results were obtained by B. A. Patil et al. [17]. The high loss tangent (tan) value at low frequencies is due to the high resistivity due to grain boundaries, so that a lot of energy is used to exchange electrons between $\mathrm{Fe}^{2+}$ and $\mathrm{Fe}^{3+}$ ions [14]. Whereas at high frequencies, electron transfer requires a small amount of energy due to its low resistivity [16]. Several factors influence the $\tan \delta$ value, including structural homogeneity, $\mathrm{Fe}^{2+}$ content, stoichiometry, and anneal temperature $[14,16]$.

\section{CONCLUSION}

Although the impedance values of the three samples have a decreasing trend with increasing frequency, $\mathrm{MnFeO}_{3} / \mathrm{ZnFe}_{2} \mathrm{O}_{4}$ and $\mathrm{MnFeO}_{3} / \mathrm{ZnFe}_{2} \mathrm{O}_{4} / \mathrm{LaMnO}_{3}$ composites are more suitable to be applied as ferrite cores when compared to $\mathrm{MnFeO}_{3}$. This can be seen from the results obtained, namely at the same frequency, the multi-phase impedance of $\mathrm{MnFeO}_{3} / \mathrm{ZnFe}_{2} \mathrm{O}_{4}$ and $\mathrm{MnFeO}_{3} / \mathrm{ZnFe}_{2} \mathrm{O}_{4} / \mathrm{LaMnO}_{3}$ is smaller than that of single phase $\mathrm{MnFeO}_{3}$. This can reduce losses due to eddy currents. While the conductivity of all samples is relatively constant at low frequencies and increases at high frequencies. The dielectric constant and loss tangent for all samples have higher values, decrease quite sharply at low frequencies and tend to remain at high frequencies. The dielectric constant and loss tangent for all samples have higher values, decrease quite sharply at low frequencies and tend to remain at high frequencies. However, the loss tangent values for multi-phase $\mathrm{MnFeO}_{3} / \mathrm{ZnFe}_{2} \mathrm{O}_{4}$ and $\mathrm{MnFeO}_{3} / \mathrm{ZnFe}_{2} \mathrm{O}_{4} / \mathrm{LaMnO}_{3}$ were higher than the single phase $\mathrm{MnFeO}_{3}$ samples.

\section{ACKNOWLEDGEMENT}

This research work was funded by Pelita Harapan University through contract No. P-041-FIP/V/2019, Study of Magnetic Functional Materials Based on Metal-Ferrite-Ground-Metal Transition Combinations for Ferrite Core Applications.

\section{REFERENCES}

[1] M. V. Nikolic, J. B. Krstic, N. J. Labus, M. D. Lukovic, M. P. Dojcinovic, M. Radovanovic, and N. B.Tadice, "Structural, morphological and textural properties of iron manganite $(\mathrm{FeMnO})$ thick films applied for humidity sensing", Materials Science and Engineering: B, vol. 257, pp. 114547, 2020.

[2] C. S. Bongu, J. Ragupathi, and K. Nallathamby, "Exploration of $\mathrm{MnFeO}_{3} /$ Multiwalled Carbon Nanotubes Composite as Potential Anode for Lithium-Ion Batteries”, Inorg. Chem, vol. 55, pp 11644-11651, 2016. 
[3] H. Bin, Z. Yao, S. Zhu, C. Zhu, H. Pan, Z. Chen, C. Wolverton, and Di Zhang, "A high-performance anode material based on $\mathrm{FeMnO}_{3}$ /graphene composite”, Journal of Alloys and Compounds, vol. 695, pp. 1223-1230, 2017.

[4] A. Aziz, E. Ahmed, I. Ali, M. Athar, M. F. Ehsan, and M. N. Ashiq, "Effect of Gd and Cu on the Structural, Electrical, and Dielectric Properties of $\mathrm{MnFeO}_{3}$ Nanomaterials Synthesized by the Sol-Gel Method", Journal of ELECTRONIC MATERIALS, vol. 44, No. 11, pp. 4300-4307, 2015.

[5] S. B. Khan, S. Irfan, and S. -L. Lee, "Influence of Zn Doping on Ni-Based Nanoferrites; $\left(\mathrm{Ni}_{1-\mathrm{x}} \mathrm{Zn}_{\mathrm{x}} \mathrm{Fe}_{2} \mathrm{O}_{4}\right)$ ", Nanomaterials, vol. 9(7), pp.1024, 2019]

[6] A. S. Džunuzovic', M. M. V. Petrovic', N. I. Ilic', J. D. Bobic', and B. D. Stojanovic', "Magneto-dielectric properties of ferrites and ferrite/ferroelectric multiferroic composites", Processing and Application of Ceramics, vol. 13 (1), pp. 104-113, 2019.

[7] J. Zhang, Y. Zhang, X. Wu, Y. Ma, S. -Y. Chien, R. Guan, D. Zhang, B. Yang, B. Yan, and Jinghai Yang, "Correlation between Structural Changes and Electrical Transport Properties of Spinel $\mathrm{ZnFe}_{2} \mathrm{O}_{4} \mathrm{Nanoparticles} \mathrm{under}$ High Pressure”, ACS Appl. Mater. Interfaces, vol.10, pp. 42856-42864, 2018.

[8] A. Sanida, S. G. Stavropoulos, T. Speliotis, and G. C. Psarras, "Investigating the Effect of Zn Ferrite Nanoparticles on the Thermomechanical, Dielectric and Magnetic Properties of Polymer Nanocomposites", Materials, vol 12 (18), pp. 3015, 2019.

[9] R. A. Fezei, N. Sdiri, K. H. Naifer and M. Férid, "Dielectric properties of calcium-substituted lanthanum ferrite", Journal of Asian Ceramic Societies, vol 8 (1), pp 94-105, 2020.

[10] M. Djahmoum, O. E. Kechaï, and P. Marchet, "Elaboration and Characterization of Materials from the $\mathrm{LaMnO}_{3}$ $\mathrm{BiMnO}_{3}$ Binary System”, Phisica status solidi (a), Wiley, In press, vol. 217(6), 2020.

[11] C. Doroftei, "Nanostructured Perovskites for Catalytic Combustion", Nanostructure in Energy Generation, Transmition and Storage, Ch. 5, pp. 75-93, 2018.

[12] S. G. Titova, S. Ch. Estemirova, and V. F. Balakirev, "Temperature Evolution Of The LaMnO $3+\mathrm{x}$ Crystal Structur", in AIP Conference Proceedings, pp. 1185, 2006.

[13] C. Wongyara, P. Harnkar, C. Suwanchawalit, T. Puangpetch, K. Laohhasurayotin, and A. Patil, "Preparation of Magnetic Zinc Ferrite Nanoparticles and their Photocatalytic Performance”, Key Engineering Materials, vol. 757, pp 125-130, 2017.

[14] M. A. Darwish, A. V. Trukhanov, O. S. Senatov, A. T. Morchenko, S. A. Saafan, K. A. Astapovich, S. V. Trukhanov, E. L. Trukhanov, A. A. Pilyushkin, A. S. B. Sombra, D. Zhou, R. B. Jotania, and C. Singh, "Investigation of ACMeasurements of Epoxy/Ferrite Composites", Nanomaterials, vol. 10 (3), pp 492, 2020.

[15] Ž. Cvejić, S. Rakić, St. Jankov, S. Skuban, and A. Kapor, "Dielectric Properties of Nanosized $\mathrm{ZnFe}_{2} \mathrm{O}_{4}$ ", in Processing and Application of Ceramics 2(1), pp. 53-56, 2008.

[16] P. Shankar, B. Shetty, A. L. Jayasheelan, N. R. S. Reddy, and C. S. Prakash, "Structural, Electrical, and Impedance Spectroscopy Studies of Barium Substituted Nano Calcium Ferrites Synthesized by Solution Combustion Method", Journal of Nanostruct, vol. 9(2), pp. 202-210, 2019.

[17] B. A. Patil, Jitendra S. Kounsalye, K. M. Jadhav, and R. D. Kokate, "Enhancement in DC Electrical Resistivity and Dielectric Behaviour of $\mathrm{Ti}^{4+}$ Doped $\mathrm{CoFe}_{2} \mathrm{O}_{4} \mathrm{NP}^{4}$ 's for Nanoelectronics Application", International Journal of Innovative Technology and Exploring Engineering (IJITEE), vol. 9 issue-6, pp. 257-262, 2020.

[18] A. A. Sattar, D. E. El-Nashar, W. R. Agami, and M. Adel Aly, "Mechanical and dielectric properties of cobalt-zinc nanoferrite/nitrile butadiene rubber composites", Journal of Thermoplastic Composite Materials, vol. 31(1), pp. 3$22,2018$. 